\title{
Videovigilancia y segregación espacial en tiempos del neoliberalismo autoritario. El caso de Los Cabos, Baja California Sur (México)*
}

DOI: https://doi.org/10.18046/recs.i31.3668

\section{Video Surveillance and Space Segregation in the Times of Authoritarian Neoliberalism. The Case of Los Cabos, Baja California Sur (México)}

\author{
Jesús Bojórquez-Luque ${ }^{* *}$ \\ Universidad Autónoma de Baja California Sur (Los Cabos, México)
}

Manuel Ángeles***

Universidad Autónoma de Baja California Sur (La Paz, México)

Alba E. Gámez ${ }^{* * * *}$

Universidad Autónoma de Baja California Sur (La Paz, México)

\begin{abstract}
* Este artículo ha sido elaborado dentro de la línea de investigación Producción del Espacio Turístico, a la cual los autores están adscritos en calidad de investigadores. Artículo de investigación recibido el 11.08.2019 y aceptado el 20.11.2019.

** Doctor en Historia por la Universidad Autónoma de Sinaloa (México). Magíster en Economía del Medio Ambiente y de los Recursos Naturales de la Universidad Autónoma de Baja California Sur (México). Sociólogo de la Universidad Autónoma de Sinaloa (México). Profesor del Departamento de Economía de la Universidad Autónoma de Baja California Sur, extensión Los Cabos (México). Correo electrónico: jesbojorquez7o@hotmail.com ORCID: https://orcid.org/ooooooo2-1745-4979

*** Doctor en Relaciones Internacionales por la Universidad de Colima (México). Magíster en Economía de la New School for Social Research (Estados Unidos). Licenciado en Economía de la Universidad de Columbia (Estados Unidos). Profesor-Investigador del Departamento de Economía de la Universidad Autónoma de Baja California Sur (México). Correo electrónico: manan@uabcs.mx ORCID: https://orcid.org/oooo-ooo3-1275-9535

**** Doctora en Relaciones Internacionales por la Universidad de Essex (Gran Bretaña). Magíster en Estudios Internacionales de la Universidad Autónoma de Barcelona/CIDOB (España). Licenciada en Economía de la Universidad Autónoma de Baja California Sur (México). Profesora-investigadora del Departamento de Economía de la Universidad Autónoma de Baja California Sur (México). Correo electrónico: agamez@uabcs.mx ORCID: https://orcid.org/oooo-ooo2-4324-0384
\end{abstract}




\section{Cómo citar/How to cite}

Bojórquez-Luque, Jesús; Ángeles, Manuel; Gámez, Alba E. (2020). Videovigilancia y segregación espacial en tiempos del neoliberalismo autoritario. El caso de Los Cabos, Baja California Sur (México). Revista CS, 31, 217-242. https://doi.org/10.18046/recs.i31.3668 


\section{Resumen}

En un contexto de aguda segregación espacial derivada de procesos de privatización de las playas y el paisaje costero en el Corredor Turístico de Los Cabos (Baja California Sur, México), la amenaza del crimen organizado al funcionamiento de las cadenas hoteleras internacionales ha sido respondida por el gobierno estatal con esquemas de videovigilancia y la criminalización de actos que se considere atenten contra los intereses turísticos en la zona. En este trabajo se emplean los conceptos de neoliberalismo autoritario, asociados a un tipo de producción del espacio, para analizar el fenómeno de videovigilancia en un contexto de conflictos y tensiones sociales auspiciadas por el propio modelo de crecimiento turístico en la región cabeña. Se utilizó una metodología cualitativa, recurriendo al trabajo de campo mediante observación por el área de estudio, análisis de bibliografía pertinente y reportes de prensa.

PALABRAS CLAVE:

neoliberalismo autoritario, segregación, videovigilancia, Los Cabos

In a context of acute spatial segregation derived from beaches' privatization processes and the coastal landscape in the Los Cabos Tourist Corridor (Baja California Sur, Mexico), the state government has responded to the threat of organized crime to the functioning of international hotel chains with video surveillance schemes and the criminalization of acts considered to be against tourist interests in the area. This paper uses the concepts of authoritarian neoliberalism associated with a type of space production to analyze the phenomenon of video surveillance in a context of conflicts and social tensions under the auspices of the tourism growth model in Los Cabos region. A qualitative methodology was used, relying on field work by observing the study area, analysis of relevant bibliography, and press reports.

\section{KEYWORDS:}

Authoritarian Neoliberalism, Segregation, Video Surveillance, Los Cabos 



\section{Introducción}

En las últimas décadas han aumentado considerablemente, en México, la inseguridad asociada al narcotráfico, la concentración del ingreso y la protesta social. La manera de contener los efectos de esta situación en el tejido social y en el ánimo de la sociedad ha sido el reforzamiento de los aparatos represivos y de vigilancia del Estado. De 2008 a 2015, el número de policías en el país creció $61 \%$, lo que en términos de gasto representó pasar de 27259 millones de pesos (mdp) a 43957 mdp, equivalente a 1,4\% del gasto total del Gobierno federal (Ethos Laboratorio de Políticas Públicas, 2017). Pese a ello, México es considerado uno de los países más violentos del mundo (Alonso, 2017).

De acuerdo con el Índice de Paz en México (Institute for Economics and Peace, 2018), 2017 fue el año más violento de los últimos años con 29 ooo homicidios, lo que significó una cantidad de 24 por cada 100 ooo habitantes, resultando un incremento del $25 \%$ anual. De estos homicidios, $69 \%$ fue por el uso de armas de fuego; asimismo, la tasa de delitos con violencia aumentó $15,2 \%$ respecto de 2016 . De las 32 entidades federativas que tiene México, solo 3 mejoraron en su nivel de paz. La violencia tuvo un gran impacto en términos económicos para el país, pues representó 4,72 billones de pesos, lo que se tradujo en $21 \%$ del PIB del país.

En ese cruento 2017, la entidad de Baja California Sur ocupó el nada honroso primer lugar como el estado menos pacífico, seguido por los estados de Guerrero, Baja California, Colima y Zacatecas. Las cifras que catapultaron a Baja California Sur como el estado más inseguro fueron: la tasa de homicidios se triplicó de un número ya alto de 34 asesinatos por cada 100 ooo habitantes, a 94 homicidios hacia el término de 2017, donde la utilización de armas de fuego en dichos ilícitos fue del $87 \%$ (Institute for Economics and Peace, 2018).

En Baja California Sur, que por sus características de cierto aislamiento, por ser parte de la península de Baja California, se había mantenido blindada de la violencia y el crecimiento de los índices delictivos de gran parte del país, esta situación empezó a cambiar cuando el 31 de julio de 2014 empezaron las disputas del crimen organizado por la venta de drogas en la ciudad de La Paz, capital del estado. Esto obligó al gobierno estatal a pedir ayuda de la federación, lo que implicó triplicar la presencia de fuerzas militares en la entidad (Santiesteban, 2018); después de ello, la violencia se trasladó al destino turístico Los Cabos, por lo que dicha violencia puso en jaque a los gobiernos local y estatal, así como a la clase empresarial turística. Una de las respuestas fue implementar el proyecto Centinela, para reforzar los dispositivos de seguridad como una forma de combatir e inhibir los brotes de inseguridad en la zona más emblemática de la economía turística sudcaliforniana. 
El proyecto Centinela se materializó en el llamado Corredor Turístico de Los Cabos, una autopista de 33 kilómetros que une a los dos principales centros urbanos del municipio: San José del Cabo (cabecera municipal) y Cabo San Lucas. En dicho corredor están establecidos hoteles de gran turismo de cadenas internacionales y es, por obvias razones, la zona donde principalmente se reproduce el capital, por lo que para las autoridades y los empresarios turísticos era importante reforzar los dispositivos de seguridad, con el objetivo de proteger sus inversiones y el flujo de turistas que hacen posibles los procesos de acumulación.

Lo anterior tiene repercusiones relevantes en la forma en que se estructura la relación Estado-sociedad en esa zona, en la propia consolidación de la segregación del espacio y de la población no privilegiada, y en el surgimiento de conflictos sociales derivados de esos fenómenos, como la privatización de las playas y el paisaje (Bojórquez-Luque; Ángeles; Gámez, 2015; Bojórquez-Luque; Ángeles, 2019). En este trabajo se emplean los conceptos de neoliberalismo autoritario asociados a un tipo de producción del espacio para analizar el fenómeno de videovigilancia en un contexto de conflictos y tensiones sociales auspiciados por el propio modelo de crecimiento turístico en la región cabeña. Así mismo, se analiza la prensa como testimonio del proyecto de seguridad implementado en el corredor turístico, sumado a un recorrido de campo para la ubicación de las cámaras instaladas en ese espacio geográfico.

\section{Neoliberalismo autoritario}

Desarrollado inicialmente por Bruff (2014), el concepto de neoliberalismo autoritario adelanta que el modelo económico neoliberal -expresado en procesos de desregulación del sector privado y políticas de reducción del Estado de bienestar-tiende a reforzar los mecanismos de control a partir de la limitación de la protesta social y de la sanción a toda conducta que ponga en riesgo el funcionamiento de ese modelo. El andamiaje constitucional y jurídico que acota combate y aísla los movimientos de protesta social mina los valores de la democracia occidental (Bruff, 2014). Sin embargo, paradójicamente, el reforzamiento del aparato represivo estimula revueltas civiles y populares que se manifiestan contra el aumento del presupuesto para cuerpos policíacos, ejército y demás fuerzas de coerción. Por tanto, Bruff y Starnes (2019) señalan que el neoliberalismo no se debe satanizar por promover el libre mercado, sino por la imposición del modelo en el mundo a partir de la coerción, de imponer a los conglomerados humanos el dominio del poder financiero, de la acumulación desmedida, de la privatización de los activos públicos o bienes comunes, todo a partir de la imposición de una serie de reformas en los entramados constitucionales 
o legales en la mayoría de los países del mundo (Bruff; Burak, 2019), de ahí que resulte fundamental la resistencia, desde los hogares, de cada uno de los ciudadanos, para minar su fuerza y cambiar la forma de ver la vida ante la imposición neoliberal (Bruff; Starnes, 2019).

En los últimos años, los movimientos sociales que han surgido son expresión de resistencia ante una forma de capitalismo que se distingue por una gran explotación laboral, de desregulación del marco de las relaciones laborales con el fin de la llamada flexibilidad laboral y la búsqueda de una supuesta mayor productividad; de un sistema económico basado en el despojo de bienes comunes, pero dichos movimientos han sido criminalizados tanto por los poderes fácticos ligados a las élites económicas, como por los poderes políticos en clara alianza, aplicándoles la política de tolerancia cero. En ese tenor, esta política de criminalización busca higienizar los espacios públicos, privatizarlos y controlarlos para contener a esos sectores que ponen en peligro a los beneficiarios del modelo, de atemperar a esa disidencia colectiva que asume una posición crítica ante la desigualdad naturalizada por quienes dirigen las políticas económicas y sociales (Maqueda, 2015), aumentando las penalidades a la protesta en las calles, disminuyendo la edad penal de los jóvenes, y afinando tácticas de linchamiento mediático contra quienes alteren la paz social y pongan en riesgo el supuesto ambiente democrático que impera.

Aunque las manifestaciones autoritarias han estado presentes en etapas previas al neoliberalismo (Ryan, 2017) y en otro tipo de regímenes económicos y políticos, el llamado triunfo de la democracia occidental no ha desterrado las formas autoritarias. Nuevas formas de represión y de fortalecimiento de los aparatos de seguridad han sido apuntaladas ante altos índices de violencia e inseguridad que reflejan una sociedad polarizada económicamente. Ello se traduce en una segregación socioespacial que se manifiesta en islas de seguridad, que buscan proteger los espacios de reproducción del capital y las zonas donde habitan las élites (Bojórquez-Luque; Ángeles; Gámez, 2018).

Chile ha sido ejemplificado como uno de los casos más ilustrativos de la imposición de políticas neoliberales en Latinoamérica, aplicadas incluso antes que en Inglaterra y en Estados Unidos y que fueran instauradas en gran parte del mundo subdesarrollado. La política económica de Chile bajo el pinochetismo (1973-1990), los principios de la ortodoxia neoliberal promovida por Milton Friedman, Arnold Harberger y Friedrich von Hayek, y los llamados Chicago Boys (Ryan, 2017: 98) se combinaron con un golpe de Estado contra el gobierno del presidente Salvador Allende, apoyado por los cuerpos de inteligencia de Estados Unidos. Aunque el concepto de neoliberalismo autoritario se planteó después de Pinochet, el uso posterior de la fuerza contra la población y opositores al régimen por la junta militar se acomoda a 
las características represivas y de reforzamiento de los aparatos de seguridad ante un modelo que fragmenta y polariza a la sociedad.

En el caso europeo, se han identificado dos momentos del autoritarismo neoliberal: el del Reino Unido, liderado por Margaret Thatcher (1979-1990); y las exigencias de la Unión Europea de disciplina financiera a Grecia en este siglo, enmarcada en una política de austeridad extrema. En aras de corregir los desequilibrios macroeconómicos impuestos, la crisis griega de 2007 reforzó políticas públicas impopulares y autoritarias, pese al rechazo masivo de la población, que fue repelida por las fuerzas del orden (Ryan, 2019).

La crisis que experimenta la democracia en diversos países denota el aumento de los rasgos autoritarios del neoliberalismo, dado que no se busca subsanar las problemáticas presentes a través de la participación ciudadana ni el empoderamiento de los diferentes sectores de la sociedad, sino la concreción de una serie de leyes, cambios constitucionales que aseguren la criminalización de todo acto que ponga en riesgo a los beneficiarios del modelo (Ryan, 2017). La vigilancia, control y criminalización de la disidencia de los grupos subordinados no es un rasgo nuevo del Estado, pero herramientas como internet han construido un gran panóptico tecnológico. Los gobiernos (y empresas) pueden ubicar a usuarios, a través de la recopilación de sus datos de ubicación con o sin su conocimiento, que eventualmente pueden servir para criminalizar las manifestaciones del descontento social (Hurley, 2017).

En el caso del gobierno estadounidense contemporáneo, la tendencia es convertir el Estado en un ente cada vez más represor, que restringe las libertades civiles usando el elemento racial como parte de un discurso que justifica, por ejemplo, medidas antiinmigrantes (Gonzales, 2017). Necesitando la economía estadounidense a los inmigrantes indocumentados, por ser mano de obra esencial en el campo, la industria y el sector de servicios, las medidas de criminalización los precarizan e invisibilizan. Esto, a su vez, se torna en una gran ventaja para el sector patronal que los emplea bajo condiciones de explotación laboral.

La vigilancia de los ciudadanos por el Estado neoliberal ha sido justificada con un discurso de lucha contra el crimen organizado y el terrorismo, que se legitima "para garantizar la propia seguridad de los ciudadanos". El discurso de defensa de la democracia liberal utiliza el miedo como justificación del reforzamiento de los dispositivos de control, aprovecha la despolitización social (Nagy, 2017) y justifica que los gobiernos actúen fuera de la esfera democrática. Paralelamente, y con su anuencia, ha surgido una economía de la seguridad privada (y militar) que complementa el accionar del Estado.

En Asia, ante la crisis económica de principios de los 2000, se reforzaron con dispositivos de seguridad en países donde se aplica la ortodoxia neoliberal, sin mejorar 
los mecanismos democráticos, poniendo en tela de duda la relación intrínseca entre el modelo económico y la democracia como elementos inseparables (Springer, 2009).

En Argentina, la implementación del modelo neoliberal durante la presidencia de Menem (1989-1999) significó la reducción del Estado benefactor y el reforzamiento del sistema penal para reprimir toda manifestación de alteración del orden impuesto. Adicionalmente, las políticas de compensación social fueron minimizadas y abandonada la idea del bienestar como un derecho (Hathazy, 2013); pero se dictaron leyes para acabar con los juicios contra las dictaduras militares del pasado, garantizando impunidad a las élites militares y sus cómplices.

La aplicación del modelo neoliberal durante el gobierno de Alberto Fujimori, en Perú, (1990-2000) se representó en políticas de austeridad económica que causaron una mayor pobreza y desigualdad (Levitt, 2000), que fueron acompañadas del reforzamiento de los aparatos represivos del Estado. Las posteriores estrategias antiterroristas para reducir el crimen en las ciudades reforzaron las policías municipales y organizaciones de vecinos para dicho objetivo. A la par, creció la estructura del poder judicial, aunque sin mejorar su forma de actuación, de modo que el sistema carcelario, caracterizado por su hacinamiento, colapsó a pesar de haberse ampliado (Hathazy, 2013).

En Egipto, se llevan a cabo políticas de control y monitoreo dirigidas a personas que generan sospechas por su condición social. La policía se dedica a detener personas, se les exigen sus documentos de identidad, y suelen ser llevados a los departamentos de policía, donde se les interroga. Esta táctica de seguridad está dirigida a sujetos de los barrios más pobres que son registrados en una base de datos policial, para llevar un control de este segmento de la población (Ismail, 2011).

\section{Videovigilancia en el neoliberalismo autoritario}

Uno de los rasgos característicos del neoliberalismo autoritario es el reforzamiento de los mecanismos de control social, a través de la canalización de amplios recursos a los aparatos represivos del Estado, la promoción de cuerpos privados de seguridad y la inversión en tecnología, como forma de contener los índices delictivos que pongan en riesgo los lugares donde se reproduce el capital o donde habita el segmento social privilegiado económicamente. En ese contexto, la aplicación de políticas penales agresivas ha sobrepoblado las cárceles, además de expandir penalidades intermedias como prisión domiciliaria y trabajos comunitarios, entre otros, empleando dispositivos electrónicos que controlan la ubicación de las personas y registran constantemente sus datos (Rodríguez, 2008). 
En las ciudades, estructuradas en un marco de segregación que excluye a grandes franjas de la población, la demanda creciente de seguridad ha legitimado el aumento de sistemas de seguridad, de gated communities (barrios residenciales cerrados), el aumento de compañías de seguridad privada, rejas electrificadas, etc. Las ciudades tienen enemigos interiores (Castro, 2009), a los que se combate con el aumento en los presupuestos de los aparatos represivos y la utilización de dispositivos digitales para la seguridad de los sectores más dinámicos de la economía (Angulo, 2016). Así, dentro de esa tendencia de la neoliberalización del espacio, estos regímenes que se han conformado democráticamente, diseñan todo un conjunto de estrategias para proteger los espacios de reproducción del capital, donde se manifiesta la dinamización de los circuitos financieros, higienizándolos de la presencia de los indeseables, de elementos conflictivos, limitando el espacio público (Bruff; Burak, 2019).

Ante un crecimiento desmedido de la inseguridad en muchos países, lo que demostró la incapacidad del Estado para enfrentarla (Espínola, 2013), en los años noventa del siglo pasado se gira a un discurso del miedo como basamento de la necesidad de seguridad. En lugar de reforzar la cohesión social y la vida comunitaria, se impulsaron estrategias de consumo, ocio y desconfianza respecto a los miembros de las clases más necesitadas. Este discurso contrasta con la tendencia a desaparecer de la seguridad social, y precariza las condiciones sociales de la población (Seghezzo; Dallorso, 2016).

La videovigilancia asociada a la aplicación del modelo neoliberal clasifica y estereotipa a los individuos, y convierte el espacio público en una especie de mercancía en donde se vigila a quienes convergen en él (Soto, 2019). Como afirman Lio y Urtasun (2016), el uso de la tecnología digital en términos de vigilancia no es más que la expresión de las relaciones de dominación, que espacialmente se traducen en el reforzamiento de zonas de grandes intereses económicos para las élites, como las áreas turística, financiera, comercial o administrativa.

En esas relaciones de dominación, la interacción entre grupos de distinto carácter, ya sea étnico, político o social, queda fracturada a partir de un espacio segregado, fragmentado, por lo que el tejido social es debilitado por las condicionantes impuestas por las élites en aras de su seguridad y la contención del distinto, del indeseable que rompe con la armonía estética que representan sus valores dominantes basados en el consumismo. El espacio público es diseñado a partir del imperativo del consumo: islas despersonalizadas que tienen como objetivo la atomización de entes, y que solo los une con quienes converge su deseo o impulso individual por la obtención de lo superfluo, donde su conjunto arquitectónico busca solo llenar, sin contenido comunitario, edificios funcionales para sus objetivos acumulativos desde el punto de vista material, espacios desodorizados, útiles para efectos del ocio lucrativo, con 
mecanismos de control y seguridad (Sequera, 2014), a partir de fuerzas del orden y tecnologías de dispositivos de seguridad como cámaras de videovigilancia.

Si bien el espacio público por excelencia de este capitalismo neoliberal se expresa en centros comerciales y espacios para el ocio, los espacios que de manera histórica han sido punto de convergencia para los seres humanos de diversos estratos sociales, como las plazas, las calles y los parques, poco a poco han tendido a neoliberalizarse, limitando su uso, controlando su accesibilidad, siendo invadidos por cámaras, y llevándose a cabo en muchas ciudades su gentrificación, con beneficio para los especuladores inmobiliarios, abonando a la segregación residencial y económica (Morgani; Raffani, 2012).

En la actualidad, nos enfrentamos a una tendencia a la consolidación del establecimiento de los dispositivos de control, que buscan imponer la disciplina de los cuerpos y de las mentes, con el objeto de consolidar la neoliberalización del espacio, brindando seguridad a los libres flujos de capital y asegurando la ampliación de sus ganancias, por lo que las desigualdades y la polarización que eso significa pondrían en riesgo las áreas de consumo y ganancia. Estos dispositivos de control han tomado carta de naturalización en el imaginario colectivo a través de la conquista ideológica reforzada por la clase política y empresarial, donde el discurso pone a la seguridad como la demanda más sentida de la ciudadanía, haciendo creer que las cámaras de seguridad y las redes de videovigilancia les proporcionarán de manera automática el halo protector en contra de los actos delictivos que atenten contra la tranquilidad social (García-Fanlo, 2015).

Mientras los centros de reproducción del capital son reforzados con videocámaras, los espacios donde vive la clase trabajadora se caracterizan por estar sumergidos como territorios de exclusión, expresándose en la inseguridad y la violencia simbólica que significa la polarización socioespacial que promueve la ciudad neoliberal. Así, dichos asentamientos son afectados por barreras físicas, tratados como apestados, como peligrosos, que amenazan el statu quo, a los cuales se estigmatiza socialmente como indeseables (Maqueda, 2015).

Aunque la videovigilancia lleva décadas de implementación, floreciendo en la mayor parte del mundo, sus efectos en la reducción de la inseguridad y criminalidad no han sido demostrados, de ahí que se asegure que lo único que proporcionan dichas tecnologías es "seguridad o tranquilidad subjetivas" (Ruiz, 2014:311), ya que las imágenes que capturan no han sido solución para el combate al delito (Galdon, 2015), por lo que su popularización se esconde a partir del discurso del miedo permanente, en un modelo consumista donde todo se vende, hasta estos discursos, siendo aprovechados por gobiernos y empresas que lucran con la adquisición de los equipos, ya sea destinados como parte del presupuesto público o por la adquisición 
de particulares que han internalizado el imaginario del temor, canalizando grandes recursos a la cuestión de seguridad.

En México, la videovigilancia fue impulsada a principios de los años ochenta, pero tomó forma evidente en la década siguiente. La distribución de cámaras no se da a partir del número de habitantes, sino en función de la generación de capital o la existencia de centros de poder político. En la Ciudad de México, Iztapalapa-que es la alcaldía de mayor población- tiene asignadas trece videocámaras por cada cien mil habitantes; pero en Cuauhtémoc, en la cual se concentran actividades económicas y la representación de los poderes políticos, hay alrededor de 31 videocámaras por cada cien mil, a pesar de contar con un número menor de habitantes (Soto, 2019).

En China, con una economía de mercado y con un sistema político autoritario, se ha extendido de manera significativa el control ciudadano, a partir de dispositivos de seguridad, mediante lectura facial, así como 170 millones de cámaras de videovigilancia, con perspectiva de integrar unos 400 millones más en los próximos años. Solo el metro de Shanghai tiene treinta mil cámaras, buscando identificar a individuos peligrosos o a quienes delinquen, pero también las usan para neutralizar a personas cuyos fines son el activismo político. Dicha situación en la China actual tiene que ver con el establecimiento de un Estado policial, donde lo que se busca es la seguridad que actúa con la consigna de que no haya signos de erosión en el sistema político (Aldama, 2008).

En Estados Unidos, un estudio de la Universidad Georgetown concluyó que la mitad de la población adulta del país estaba en la base de datos de la policía, gracias al uso de las tecnologías de reconocimiento facial, lo que era un signo preocupante por la violación a la privacidad de las personas y que violentaba la Constitución en materia de las libertades civiles (Alonso, 2016). Este tipo de políticas de seguridad se han extendido a partir del discurso tendiente a centrar las razones de seguridad nacional por el tema del terrorismo, la inmigración ilegal y la lucha contra el mercado de las drogas.

En el caso del municipio de Los Cabos, siendo la joya de la corona, en términos económicos, del estado de Baja California Sur, y el segundo destino turístico de litoral más importante del país -después de Cancún-, fue objeto de políticas de reforzamiento en seguridad a partir del repunte de los crímenes de alto impacto.

\section{Los Cabos, Baja California Sur}

Los Cabos es uno de los cinco municipios de los que se conforma el estado de Baja California Sur. Se encuentra en la parte más austral del estado (ver Figura 1), cuenta con una superficie de $3684 \mathrm{~km}^{2}$, que representan el $5 \%$ de la superficie de la entidad, siendo el municipio de menor territorio del estado. Los Cabos se ubica geográfica- 
mente entre los $23^{\circ} 40^{\prime}$ y $22^{\circ} 52^{\prime}$ de latitud norte, y $109^{\circ} 24^{\prime}$ y $110^{\circ}$ o $7^{\prime}$ de longitud oeste. Colinda al norte con el municipio de La Paz y el Golfo de California, al sur con el Océano Pacífico, al oeste con el municipio de La Paz y el Océano Pacífico, y al este con el Golfo de California y el Océano Pacífico (Ayuntamiento de Los Cabos, 2008).

FIGURA 1 | Municipio de Los Cabos, Baja California Sur

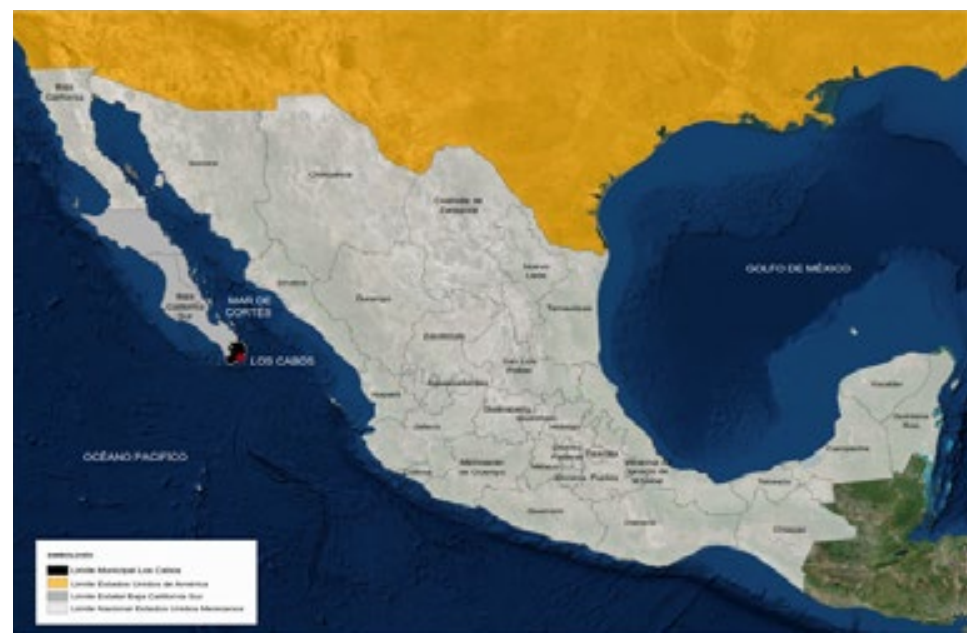

Fuente: Implan-Los Cabos (s.f.).

Los Cabos es, actualmente, el municipio del estado que mayor población tiene, estimándose, en 2015, 287671 habitantes, lo que representa el $40 \%$ del total del estado, por encima del municipio donde está la capital de Baja California Sur, La Paz (ver Cuadro 1). En cuanto a extensión territorial, es el municipio más pequeño del estado y, por lo tanto, es el más densamente poblado, pues cuenta con 63,6 habitantes $/ \mathrm{km}^{2}$, superando de manera evidente el promedio estatal que es de 8,6 habitantes/ $\mathrm{km}^{2}$. La evolución poblacional de esta región ha sido muy explosiva, pues a inicios del siglo XX, en 1900, la densidad demográfica apenas era de 2,1 habitantes $/ \mathrm{km}^{2}$, siendo propiciada por una economía que evolucionó de actividades primarias como la agricultura, la pesca y la ganadería, a una economía terciaria, enfocada principalmente al turismo, que ha sido fuente de atracción ${ }^{1}$ para ciudadanos al interior del estado y de otras entidades federativas (Vázquez, 2012). 
CUADRO 1 Número de habitantes por municipio

\begin{tabular}{|c|c|c|}
\hline Clave del municipio & Municipio & Habitantes (año 2015) \\
\hline OO1 & Comondú & 72564 \\
\hline 002 & Mulegé & 60171 \\
\hline 003 & La Paz & 272711 \\
\hline 008 & Los Cabos & 287671 \\
\hline 009 & Loreto & 18912 \\
\hline
\end{tabular}

Fuente: Instituto Nacional de Estadística y Geografía (INEGI, 2015).

Desde 1976, el municipio de Los Cabos ha sido destinatario de políticas públicas en materia de turismo, siendo el tercer Centro Integralmente Planeado (CIP) creado por el Fondo Nacional de Fomento al Turismo (Fonatur), lo cual permitió la llegada de inversiones en materia turística, aumentando la generación de infraestructura, la cual fue concentrada en la zona litoral, en San José del Cabo y Cabo San Lucas, así como en el corredor turístico de 33 kilómetros que une a las dos localidades. Sin embargo, los asentamientos destinados a los trabajadores de este sector y a las actividades asociadas a él, en su mayoría viven con deficiencias en infraestructura urbana básica, lo que fomenta un clima de marginación (Ibáñez, 2017), y violencia física y simbólica.

\section{Violencia en Los Cabos}

De ser Baja California Sur una de las entidades que gozaba de gran tranquilidad, y de la misma manera el municipio de Los Cabos, a partir de 2014 la violencia provocada por las disputas del crimen organizado por la venta de drogas generó condiciones de alarma de los tres niveles de gobierno, quienes observaban cómo el segundo destino turístico de litoral más importante del país, y fuente de cuantiosas divisas estaba en riesgo. A partir de esa realidad, la tendencia ha sido a reforzar la videovigilancia para aumentar la confianza de turistas e inversionistas. En ese sentido, buscando estrategias de seguridad, el gobierno de estado estableció el programa Centro de Comando, Control, Comunicación y Cómputo (C4), con un punto de operaciones y monitoreo en Cabo San Lucas, ciudad que muestra la concentración de mayor inversión turística (Bojórquez-Luque; Ángeles; Gámez, 2016). 
Sin embargo, a pesar del $\mathrm{C} 4 \mathrm{y}$ del incremento de los presupuestos a las corporaciones policíacas, aumentaron sustancialmente los actos delictivos ligados al narcotráfico en la región; lo que tuvo como consecuencia el anuncio del Departamento de Estado de Estados Unidos que recomendaba a sus ciudadanos no viajar al municipio, duro golpe para la actividad turística, pues son los estadounidenses el turismo más cuantioso. El crecimiento inusitado de la violencia no afectó a los turistas, sino que se manifestó de manera más cruda en las zonas marginadas de la ciudad de San José del Cabo, principalmente. No obstante, la disputa por el mercado de estupefacientes se da en un entorno que incluye a turistas como consumidores (Semple, 2017) y es auspiciado por las propias características del modelo turístico. Esto es, la violencia en los sitios turísticos está estrechamente relacionada con un modelo de crecimiento económico y poblacional que fomenta la desigualdad y la segregación social tanto en la ciudad como en las áreas públicas.

El crecimiento de la violencia se disparó en todo el estado de Baja California Sur (entre enero y octubre de 2016 se registraron 20074 delitos) (Rodríguez, 2016), pero el municipio de Los Cabos ocupó el nada honroso primer lugar en la clasificación de las cincuenta ciudades de mayor violencia en el país. La tasa de crecimiento de los homicidios fue de 111,33 por cada cien mil habitantes, que dio como resultado un aumento de casi $500 \%$, pasando de 61 asesinatos, en 2016, a 365, en 2017 (Reviejo, 2018). La Figura 2 muestra claramente ese panorama.

\section{FIGURA 2 Homicidios intencionales por arma de fuego en La Paz y Los Cabos (Baja California Sur), enero de 2011 a junio de 2017}

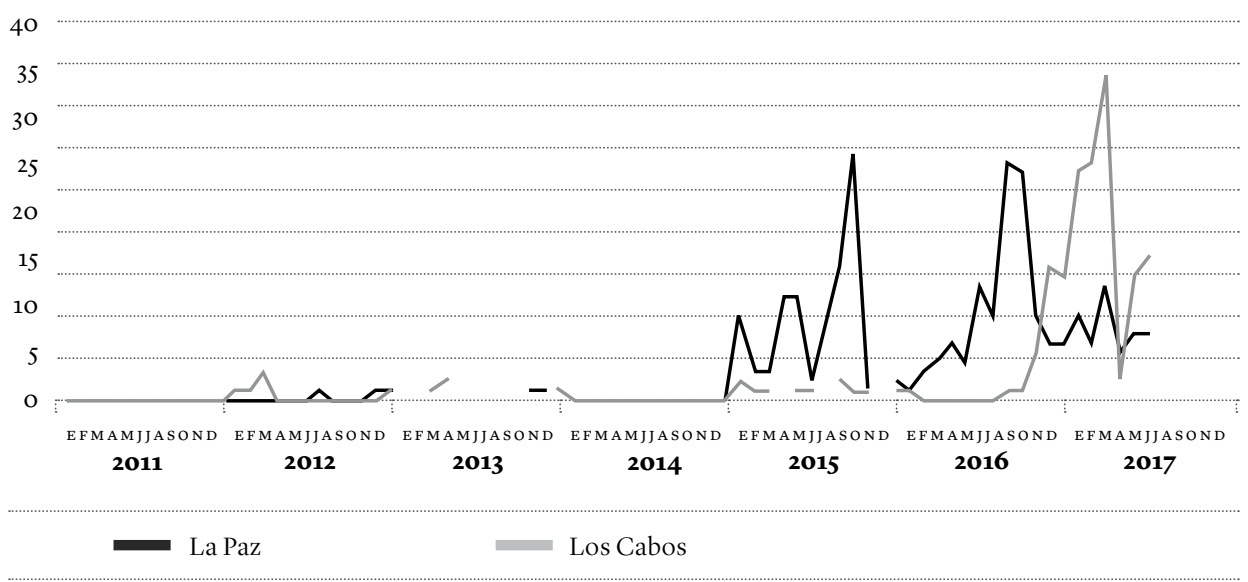


Pese a lo anterior, el presidente del Consejo Coordinador de Los Cabos (CCC), la agrupación patronal más importante e influyente del municipio, declaró que el problema de la inseguridad había sido superado y llamó a mantener la tranquilidad. El representante empresarial manifestó que lo sucedido era producto del descuido de las autoridades en materia de seguridad, al no fortalecer y corregir los visos de corrupción al interior de los cuerpos policíacos estatales y municipales, y carecer de mejor equipo y tecnología (León, 2018). Pese a que en esa manifestación el problema central del fenómeno de inseguridad era la falta de modernización de los cuerpos policíacos, como recogía la prensa (Green, 2017), dicha situación también tenía una explicación en la desigualdad social que imperaba en el municipio, lo que generaba un caldo de cultivo para el crecimiento exponencial de la violencia.

Los llamados del sector empresarial estimularon la acción del gobierno estatal, que anunció el traslado permanente de efectivos de la Gendarmería Nacional a Los Cabos, principalmente en la zona turística, con el fin de inhibir los índices delictivos. A la par, se anunció el proyecto Centinela para reforzar los dispositivos de videovigilancia en la emblemática zona del corredor de Los Cabos (ver Figura 3), corazón del dinamismo turístico del estado.

\section{\begin{tabular}{|l|l} 
FIGURA 3 & Corredor turístico de Los Cabos
\end{tabular}}

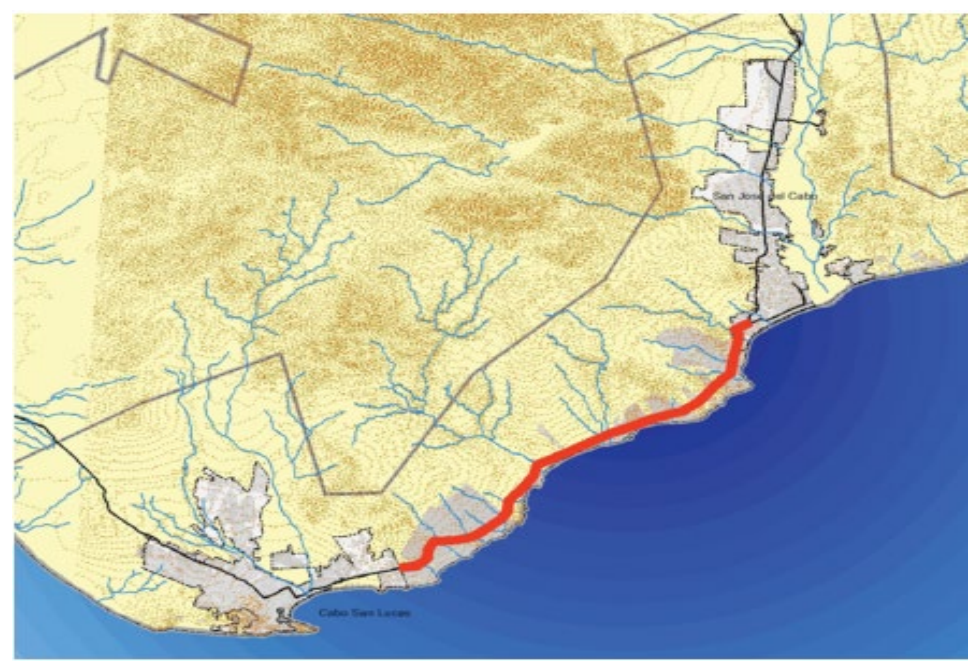




\section{Videovigilancia en Baja California Sur y proyecto Centinela en Los Cabos}

Las políticas de seguridad pública impulsadas en los últimos años en Baja California Sur se han abocado a reforzar los dispositivos digitales como parte fundamental en las estrategias de contención del delito, especialmente en las zonas de actividad de ocio y turismo. La Ley de Videovigilancia del Estado, publicada el 31 de julio de 2014, tiene como objeto:

Regular la utilización de videocámaras para grabar o captar imágenes con o sin sonidos en lugares públicos o privados abiertos a la sociedad de manera exclusiva por las instituciones de seguridad pública, por otras autoridades en los inmuebles que estén a su disposición, o bien, por empresas prestadoras de un servicio de seguridad privada (Congreso del Estado de Baja California Sur, 2016: 1).

Para atender la preocupación del sector empresarial de Los Cabos por el aumento del índice delictivo, el gobierno estatal presentó al CCC una propuesta para instalar 31 cámaras de videovigilancia en diversos puntos estratégicos del corredor turístico, desde la salida de Cabo San Lucas, hasta la glorieta del Fonatur en San José del Cabo (ver Cuadro 2). Para la concreción de dicho programa, el gobierno estatal invitó a los empresarios de la zona a encargarse de las cámaras cercanas a sus instalaciones hoteleras (“Instalarán 31 cámaras...", 2016).

De la misma manera, en voz del secretario general de gobierno, el gobierno estatal propuso en 2017 la construcción de un Centro de Operaciones de la Policía Estatal en el municipio de Los Cabos. El sector empresarial, por su parte, agrupado en el CCC, asumió el compromiso de apoyar su construcción para reforzar la estrategia de seguridad en la zona turística ("Instalarán 31 cámaras...", 2016). La instalación de las cámaras fue distribuida estratégicamente (Jaimes, 2016), de modo que en el estado sumaban 64 unidades todas funcionales (Gaxiola, 2016). Esa estrategia fue llamada proyecto Centinela, y tuvo una inversión de 480 millones de pesos, en los municipios de La Paz y Los Cabos, para la instalación de videocámaras y la modernización de la unidad de $\mathrm{C}_{4}$, en la que concurrían elementos de la Secretaría de la Defensa Nacional (Sedena), de la Secretaría de Marina (SEMAR) y del Centro de Investigación en Seguridad Nacional (CISEN), así como elementos de la Policía Federal y del Estado (“Proyecto Centinela videovigilará BCS”, 2017). 
CUADRO 2 $\mid$ Cámaras en el Corredor Turístico de Los Cabos, 2019

\begin{tabular}{|c|c|c|c|}
\hline No. & Ubicación & No. & Ubicación \\
\hline 1. & $\begin{array}{l}\text { Intersección Blvd. Constituyentes-Co- } \\
\text { rredor Turístico }\end{array}$ & 17. & Hotel Garza Blanca \\
\hline 2. & VIPS Restaurante & 18. & Hotel Hilton \\
\hline 3. & Country Club & 19. & Hotel Cabo Real \\
\hline 4. & Costco & 20. & Hotel Marquis \\
\hline 5 & Crucero Universidad de Tijuana & 21. & Westin 1 \\
\hline 6. & Cabo Bello-Home Depot & 22. & Westin 2 \\
\hline 7. & Residencial Santa Carmela & 23. & Zona Automotriz \\
\hline 8. & Hacienda Encantada Resort and Spa & 24. & Loma Encantada-Fresko \\
\hline 9. & Previo a Sheraton Hacienda del Mar & 25 . & Plaza Vieja-Volkswagen-Polaris \\
\hline 10. & Santa María 1 & 26. & Automotriz Ford \\
\hline 11. & Santa María 2 & 27. & Hotel One \& Only Palmilla \\
\hline 12. & Santa María 3 & 28. & Hotel Cabo Surf \\
\hline 13. & Chileno Bay 1 & 29. & Costa Azul \\
\hline 14. & Chileno Bay 2 & 30. & Plaza Península \\
\hline 15 . & Chileno Bay 3 & 31. & Glorieta Fonatur \\
\hline 16. & Chileno Bay 4 & & \\
\hline
\end{tabular}

El CCE anunció que todas las cámaras de videovigilancia del proyecto Centinela en el municipio de Los Cabos serían colocadas en el corredor turístico (ver Figura 4), que incluye las ciudades de San José del Cabo y Cabo San Lucas, así como el tramo de 33 kilómetros de carretera que las une y donde se encuentran instalados la mayoría de los hoteles de gran turismo que están a pie de playa. De acuerdo con las élites política y empresarial, era prioritario proteger la actividad turística de esa zona y las fuentes de empleo que representa.

Con las cámaras sería vigilada la transitada rúa, pues en ella se trasladan los trabajadores del sector turístico, turistas, materiales y la población en general de las dos localidades. Los empresarios sostenían que era una estrategia correcta, toda vez que el corredor es: 
la zona con mayor tránsito de la ciudad, es la zona donde más accidentes hay, atropellados, no solo es un asunto de seguridad es un sistema de tráfico, accidentes y todo lo que este sistema va a empujar en beneficio de la sociedad y desde luego en materia de seguridad y turistas (“Trabaja 'casi al 100\%”..., 2017).

Asimismo, el subsecretario de Seguridad Pública del estado de Baja California Sur argumentaba que, a partir de la instalación de videocámaras, se habían logrado avances en la investigación de los delitos, lo que suponía un éxito del proyecto. Personal del $\mathrm{C}_{4}$ (ver Figura 5) en Los Cabos monitorearían las cámaras de día y noche, y serían los encargados de recibir llamadas de emergencia ("Trabaja 'casi al 100\%"”..., 2017).

De acuerdo a información del gobierno estatal, las cámaras instaladas tienen tecnología de punta, con capacidad para close up y seguir la ruta de vehículos e individuos sospechosos. Cada cámara cuesta un millón de pesos, y todas estarán conectadas al Sistema Nacional de Seguridad Pública (“Inicia instalación de cámaras...”, 2017). Los recursos para la materialización del proyecto provinieron de fuentes federales

\section{FIGURA 4 $\quad$ Cámaras en el corredor turístico}
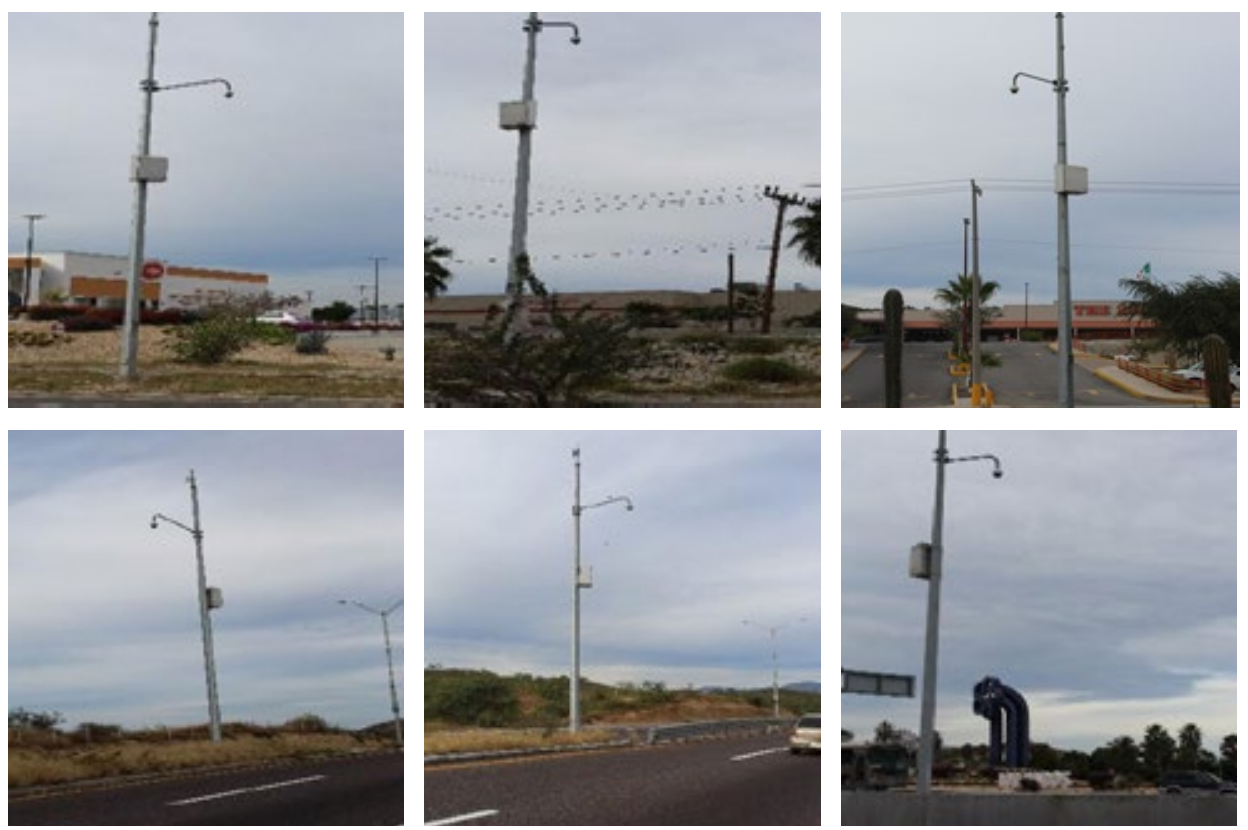
FIGURA 5 Centro de Control y Vigilancia C4 en Cabo San Lucas

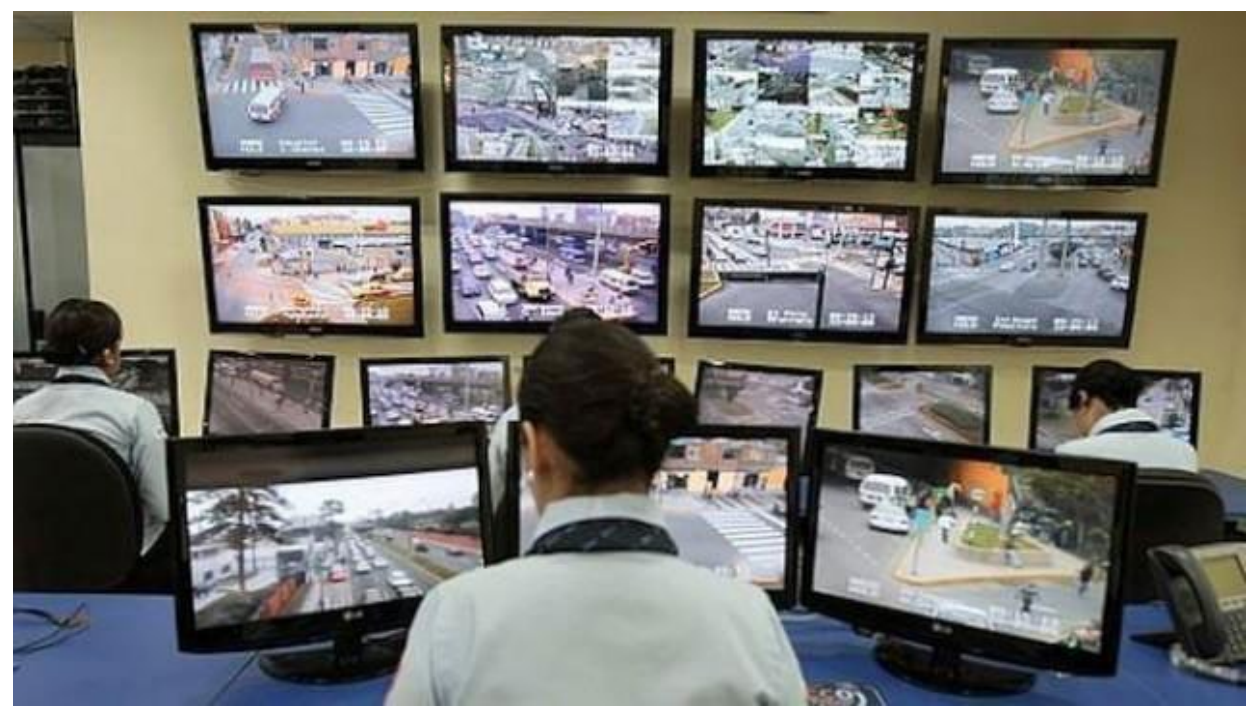

Fuente: Proyecto Centinela videovigilará BCS (2017).

y estatales, divididos en dos rubros: infraestructura y tecnología para mejorar las instalaciones del centro de comando, además de la adquisición e instalación de cámaras de videovigilancia, líneas de comunicación, software, y servidores, entre otros (“Modernizarán C4 Los Cabos", 2017).

Las 31 cámaras de videovigilancia en el corredor turístico fueron ubicadas a la altura de diversos hoteles e instalaciones del corredor turístico. En contraste, en las colonias populares de las ciudades de San José del Cabo y de Cabo San Lucas, donde la inseguridad campea, hay falta de alumbrado público, pavimentación, agua potable y alcantarillado. Esto evidencia que las políticas e inversiones en materia de seguridad del sector público se centran en y benefician a los sitios del sector empresarial turístico, donde se reproduce el capital de la industria del ocio.

En este contexto de reforzamientos de los dispositivos de videovigilancia, el presidente de la Comisión de Seguridad de la Asociación de Empresarios de Los Cabos comentó que con las cámaras instaladas en el corredor turístico y las ciudades de San José del Cabo y Cabo San Lucas (que suman 110), las cuales fueron por aportaciones de los sectores público y privado, se tienen las herramientas para, de manera coordinada, poder establecer el combate al delito, accidentes e inseguridad en la zona ("Funcionando 110 cámaras...", 2019). Asimismo, la directora de los Centros de Control, Comando, Comunicación y Cómputo $\left(\mathrm{C}_{4}\right)$ anuncia que se seguirán suman- 
do esfuerzo para la adquisición e instalación de un mayor número de cámaras, las cuales se ubicarán en zonas estratégicas de la región (“Añaden 5 cámaras...”, 2019).

\section{Conclusiones}

El capitalismo se encuentra en su etapa neoliberal, la cual tiene como rasgo característico la edificación de condiciones políticas, sociales y jurídicas que apuntalan la concentración de la riqueza en el capital financiero internacional. Una de sus expresiones en la acumulación de capital es la especulación inmobiliaria en destinos turísticos de países denominados emergentes, como México. Sin embargo, dicha política de desarrollo basado en el turismo de masas de litoral ha traído como consecuencias, en todos los países periféricos, islas de riquezas en un mar de pobreza, condiciones que son caldo de cultivo no solo de la violencia simbólica que de manera natural se expresa, sino de violencia asociada al crimen, derivada de la polarización y segregación espacial y económica que el modelo incuba.

Una de las consecuencias de la aplicación del modelo neoliberal es la generación de sociedades fragmentadas, dualizadas económica, social y políticamente, entre otros ámbitos. En el caso de Los Cabos, el turismo se ha manifestado en oportunidades de ingreso para una parte considerable de la población que ha llegado estimulada por el crecimiento turístico. Sin embargo, el modelo de enclaves en ese sector ha producido marginación, rezagos urbanos y escasas ventajas en otros ámbitos, que propician conductas sociales que trastocan la seguridad. En vez de solucionar el problema en sus causas, de tener empresas con responsabilidad social que procuren la mejora de las condiciones de vida de la población trabajadora, se opta por reforzar los aparatos represivos, sin que la violencia sea contenida.

La miopía de las autoridades, que ven la inseguridad solo como un fenómeno asociado a la desadaptación social, y no como una manifestación del modelo económico que provoca graves desigualdades sociales, con una violencia simbólica expresada en marginación, pobreza y falta de oportunidades, y en la cual sostienen que la única forma de reducir el índice de delitos es el reforzamiento de los aparatos represivos, se seguirá en el círculo vicioso, pues no se atacan las raíces profundas que dan como resultado dicha descomposición del tejido social.

En ese contexto, desasociar la violencia a las grandes desigualdades sociales que se viven tanto en San José del Cabo como en Cabo San Lucas preludia un escenario poco alentador. Hasta el momento, la respuesta de las autoridades estatales ha sido la de reforzar los aparatos represivos y los dispositivos de vigilancia y control, pero no se ha planteado atemperar las condiciones de marginación que potencian esas condiciones de violencia simbólica y enfrentamiento constante. El cambio de política 
federal en materia de seguridad podría iniciar un reenfoque en este sentido, donde se sostiene que la violencia debe ser atacada en sus causas profundas, que son la pobreza y la desigualdad social, y no solo poniéndose énfasis en el reforzamiento de los aparatos represivos.

\section{Referencias}

Aldama, Zigor (22 de abril de 2008). El Gran Hermano chino tiene ojos en todo el mundo. El Diario. Recuperado de https://www.eldiario.es/desalambre/gran-hermano-chino-ojos-mundo_o_762923942.html

Alonso, Nicolás (2016). Estados Unidos tiene registrados los rostros de la mitad de sus ciudadanos. El Pais. Recuperado de https://elpais.com/internacional/2016/10/20/estados_unidos/1476996646_669203.html

Alonso, Ruy (2017). Los 14 países más violentos del mundo. El Economista. Recuperado de https://www.eleconomista.com.mx/internacionales/Los-14-paises-mas-violentos-delmundo-20170608-0061.html

Angulo, Erika (2016). Reflexiones teóricas para una lectura del control urbano desde lo panóptico. Espacialidades, 6(2), 34-57.

Añaden 5 cámaras de videovigilancia al corredor turístico de Los Cabos; invirtieron 1,2 mdp (8 de abril de 2019). BCS Noticias. Recuperado de http://www.bcsnoticias.mx/anaden-5-camaras-de-videovigilancia-al-corredor-turistico-de-los-cabos-invirtieron-1-2-mdp/

Ayuntamiento de Los Cabos (2008). Programa de Ordenamiento Ecológico Local del Municipio de Los Cabos, BCS. Los Cabos: Municipio de Los Cabos.

Bojórquez-Luque, Jesús; Ángeles, Manuel (2019). Turismo y polarización social en Los Cabos, México. El proyecto Zona Dorada. Bitácora Urbano Territorial, 29(2), 117-126.

Bojórquez-Luque, Jesús; Ángeles, Manuel; Gámez, Alba E. (2015). Apropiación del territorio costero en Cabo San Lucas, Baja California Sur, México: los casos de las playas y la propiedad ejidal. En Sin tierras no hay paraíso. Turismo, organizaciones agrariasy apropiación territorial en México (pp. 275-306), coordinado por Gustavo Marín Guardado. Tenerife: Pasos.

Bojórquez-Luque, Jesús; Ángeles, Manuel; Gámez, Alba E. (2016). Espacios de protección del capital: panoptismo y videovigilancia en el destino turístico de Cabo San Lucas, Baja California Sur (México). Anais Brasileiros de Estudos Turísticos, 6(3), 7-20.

Bojórquez-Luque, Jesús; Ángeles, Manuel; Gámez, Alba E. (2018). Produciendo el espacio turístico: el despojo en la apropiación del territorio costero en Los Cabos, Baja California Sur (México). Teoría y Praxis, 26, 9-35. 
Bruff, Ian (2014). The Rise of Authoritarian Neoliberalism. Journal Rethinking Marxism, 26(1), 113-129. http://dx.doi.org/10.1080/o8935696.2013.843250

Bruff, Ian; Burak, Cemal (2019). Authoritarian Neoliberalism: Trajectories of Knowledge Production and Praxis. Globalizations, 16(3), 233-244. https://doi.org/10.1080/14747731 .2018 .1502497

Bruff, Ian; Starnes, Kathryn (2019). Framing the Neoliberal Canon: Resisting the Market Myth Via Literary Enquiry. Globalizations, 16(3), 245-259. https://doi.org/10.1080/14747731.20 18.150248

Castro, Rodrigo (2009). La ciudad apestada. Neoliberalismo y postpanóptico. Revista de Ciencia Política, 29(1), 165-183.

Congreso del Estado de Baja California Sur (2016). Ley de Video Vigilancia del Estado de Baja California Sur. La Paz: Congreso del Estado de Baja California Sur. Recuperado de http:// www.cbcs.gob.mx/index.php/cmply/1563-ley-video-vigilancia-bcs

Espínola, Dolly (2013). La videovigilancia en el discurso modernizador de la seguridad. Ação Midiática, 6. Recuperado de http://dx.doi.org/10.5380/am.voi6.34413

Ethos Laboratorio de Políticas Públicas (2017). Reporte Ethos. Descifrando el gasto en seguridad pública. México:Ethos. Recuperado de https://ethos.org.mx/wp-content/uploads/2017/o7/ SeguridadFnlDigital.compressed.pdf

Funcionando 110 cámaras de video vigilancia en Los Cabos (12 de marzo de 2019). Cabovisión. Recuperado de http://cabovision.tv/index.php/noticias-hidden/38697-funcionando-110-camaras-de-video-vigilancia-en-los-cabos

Galdon, Gemma (2015). Si la videovigilancia es la respuesta, ¿cuál era la pregunta? Cámaras, seguridad y políticas urbanas. Eure, 41(123), 81-101.

García-Fanlo, Luis (2015). Neoliberalismo y sociedad de normalización. Unidad Sociológica, 4(2), 9-17.

Gaxiola, Iván (3 de marzo de 2016). En BCS operan 64 cámaras de vigilancia en calles y carreteras. El Informante. Recuperado de http://elinformantebcs.mx/en-bcs-operan-64videocamaras-de-vigilancia-este-ano-entran-25-mas-en-funciones/

Gobierno del Estado de Baja California Sur (2017). Los Cabos: información estratégica. La Paz: Gobierno del Estado de Baja California Sur.

Gonzales, Alfonso (2017). Trumpism, Authoritarian Neoliberalism, and Subaltern Latina/o Politics. Aztlán: A Journal of Chicano Studies, 42(2), 147-164.

Green, Emily (8 de septiembre de 2017). What tourists need to know about the violence in Baja. KCRW. Recuperado de https://www.kcrw.com/news/articles/what-tourists-needto-know-about-the-violence-in-baja 
Hathazy, Paul (2013). (Re) Shaping the Neoliberal Leviathans: The Politics of Penality and Welfare in Argentina, Chile and Peru. European Review of Latin American and Caribbean Studies, 95, 5-25.

Hurley, Emily (2017). Surveillance Technology and the Neoliberal State: Expanding the Power to Criminalize in a Data Unlimited World [Tesis de maestría]. Virginia Polytechnic Institute and State University, Master of Arts in Political Science, Blacksburg.

Ibáñez, Reyna (2017). Propuesta de indicadores alternos, a partir de un análisis basado en indicadores convencionales y las asimetrías en municipios turísticos con destinos de sol y playa. Nova Scientia, 9(19), 850-901. http://dx.doi.org/10.21640/ns.v9i19.1078

Implan-Los Cabos (2013). Segunda actualización del Plan Director de Desarrollo Urbano de Los Cabos, B.C.S. 204O. Los Cabos: Implan-Los Cabos.

Implan-Los Cabos (s.f.). Ubicación del municipio de Los Cabos. Inédito.

Inicia instalación de cámaras de video vigilancia en corredor turístico (23 de marzo de 2017). Cabovisión. Recuperado de http://cabovision.tv/index.php/noticias-hidden/27025-inicia-instalacion-de-camaras-de-video-vigilancia-en-corredor-turistico

Instalarán 31 cámaras de videovigilancia en el corredor turístico de Los Cabos (31 de octubre de 2016). BCS Noticias. Recuperado de http://www.bcsnoticias.mx/instalaran-31-camaras-de-videovigilancia-en-el-corredor-turistico-de-los-cabos/

Institute for Economics and Peace (2018). Índices de Paz México. Evolución y perspectiva de los factores que hacen posible la paz. Recuperado de http://visionofhumanity.org/app/ uploads/2018/04/Mexico-Peace-Index-2018-Spanish.pdf

Instituto Nacional de Estadística y Geografía (2015). Baja California Sur. Número de habitantes. Recuperado de http://www.cuentame.inegi.org.mx/monografias/informacion/bcs/ poblacion/

Ismail, Salwa (2011). Authoritarian Government, Neoliberalism and Everyday Civilities in Egypt. Third World Quarterly, 32(5), 845-862. http://dx.doi.org/10.1080/01436597.2011. 578957

Jaimes, Lizbeth (28 de octubre de 2016). Anuncian 31 cámaras de video vigilancia en corredor turístico y Centro de Comando de Policía Estatal en Los Cabos: CCC. Tribuna de Los Cabos. Recuperado de https://www.tribunadeloscabos.com.mx/anuncian-31-camaras-de-video-vigilancia-en-corredor-turistico-y-centro-de-comando-de-policia-estatal-en-los-cabos-ccc/

León, Raymundo (18 de abril de 2018). IP reconoce fin de inseguridad en Los Cabos. La Jornada. Recuperado de https://www.jornada.com.mx/ultimas/2018/o4/18/ip-reconoce-fin-de-inseguridad-en-los-cabos-7637.html 
Levitt, Barry (marzo, 200o). Continuity and change in Peru's political parties, 1985-200o. Trabajo presentado en XXII Congress of the Latin American Studies Association (LASA), Miami, EE. UU.

Lio, Vanessa; Urtasun, Martín (2016). Devolviendo la mirada. Interrogantes y claves de lectura para la investigación de la videovigilancia. Delito y Sociedad, 41(25), 37-58.

Maqueda, María (2015). La criminalización del espacio público. El imparable ascenso de las “clases peligrosas". Revista Electrónica de Ciencia Penaly Criminología, 17, 1-56.

Modernizarán C4 Los Cabos (29 de mayo de 2017). Peninsular Digital. Recuperado de http:// peninsulardigital.com/extra/modernizaran-c4-los-cabos/220617

Morgani, Rodolfo; Raffani, Mariana (2012). Mendoza y los orígenes de la ciudad neoliberal. Tiempo y espacio, 28, 55-75.

Nagy, Veronika (2017). How to silence the lambs? Constructing Authoritarian Governance in Post-Transitional Hungary. Surveillance \& Society, 15(3-4), 447-455.

Proyecto Centinela videovigilará BCS (7 de mayo de 2017). Octavo Día. Recuperado de https:// octavodia.com.mx/articulo/11053/proyecto-centinela-video-vigilara-bcs

Reviejo, Isabel (7 de marzo de 2018). Los Cabos, de paraíso del turismo a ciudad más peligrosa del mundo. Clarín. Recuperado de https://www.clarin.com/viajes/cabos-paraiso-turismo-ciudad-peligrosa-mundo_o_B1PviopuG.html

Rodríguez, Gladys (24 de noviembre de 2016). Los Cabos violento: cinco muertos en 24 horas. $E l$ Universal. Recuperado de https://www.eluniversal.com.mx/articulo/estados/2016/11/24/ los-cabos-violento-cinco-muertos-en-24-horas

Rodríguez, Pablo (2008). ¿Qué son las sociedades de control? Sociedad, 27, s.p.

Ruiz, Santiago (2014). Videovigilancia en el centro de Madrid: ¿Hacia el panóptico electrónico? Teknokultura, 11(2), 301-327.

Ryan, Matthew (2017). 'Authoritarian Neoliberalism': Crisis, the State, and the Challenge of Periodization [Tesis de maestría]. Universidad de Sidney, Sidney, Australia.

Ryan, Matthew (2019). Interrogating 'Authoritarian Neoliberalism': The Problem of Periodization. Competition \& Change, 23(2), 116-137. https://doi.org/10.1177/1024529418797867

Santiesteban, Gilberto (1 de agosto de 2018). A cuatro años del inicio de la violencia en Baja California Sur. Diario El Independiente. Recuperado de https://www.diarioelindependiente. $\mathrm{mx} / 2018 / 08 / \mathrm{a}-4$-anos-del-inicio-de-la-violencia-en-baja-california-sur

Seghezzo, Gabriela; Dallorso, Nicolás (2016). Retorno neoliberal y razón securitaria. Bordes, 1(2), 123-128. Recuperado de https://publicaciones.unpaz.edu.ar/OJS/index.php/bordes/ article/view/367/334 
Semple, Kirk (16 de septiembre de 2017). Where Tourism Thrives in Mexico, Bloodshed and Poverty are Blocks Away. The New York Times. Recuperado de https://www.nytimes. com/2017/o9/16/world/americas/los-cabos-mexico-crime-tourism.html?ref=nyt-es\&mcid=nyt-es\&subid=article

Sequera, Jorge (2014). Ciudad, espacio público y gubernamentalidad neoliberal. Urban, 7, 69-82.

Soto, José (21 de enero de 2019). Videovigilancia en la Ciudad de México;instinto de BigBrother en un gobierno de izquierda. Economicón. Recuperado de https://economicon.mx/2019/o1/21/ videovigilancia-en-la-ciudad-de-mexico-instinto-de-big-brother-en-un-gobierno-de-izquierda/

Springer, Simon (2009). Renewed Authoritarianism in Southeast Asia: Undermining Democracy through Neoliberal Reform. Asian Pacific View Point, 50 (3), 271-276.

Trabaja "casi al 100\%" la videovigilancia en la transpeninsular (1 de agosto de 2017). Peninsular Digital. Recuperado de http://peninsulardigital.com/extra/trabaja-casi-al-10o-la-videovigilancia-la-transpeninsular/224474

Vázquez, Luz (2012). Cambios económicos en la región de Los Cabos a partir de una economía mercantil en las primeras décadas del S.XX hasta llegar a una economía turística [Tesis de maestría]. Universidad Autónoma de Baja California Sur, La Paz, México. 